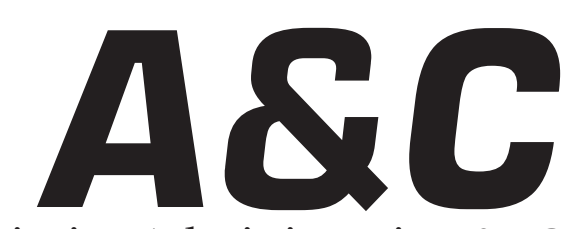

Revista de Direito Administrativo \& Constitucional

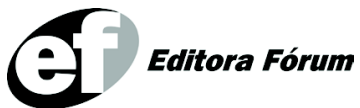

ISSN 1516-3210

A\&C R. de Dir. Administrativo e Constitucional Belo Horizonte ano 8 n. 31 p. 1-272 jan./mar. 2008 


\section{A\&C - REVISTA DE DIREITO ADMINISTRATIVO E CONSTITUCIONAL}

IPDA

Instituto Paranaense

de Direito Administrativo

Direção Geral

Romeu Felipe Bacellar Filho

Direção Editorial

Paulo Roberto Ferreira Motta

Direção Executiva

Emerson Gabardo

Conselho de Redação

Edgar Chiuratto Guimarães

Adriana da Costa Ricardo Schier

Célio Heitor Guimarães

\section{Conselho Editorial}

Adilson Abreu Dallari

Alice Gonzáles Borges

Carlos Ari Sundfeld

Carlos Ayres Britto

Carlos Delpiazzo

Cármen Lúcia Antunes Rocha

Celso Antônio Bandeira de Mello

Clèmerson Merlin Clève

Clóvis Beznos

Enrique Silva Cimma

Eros Roberto Grau

Fabrício Motta

Guilhermo Andrés Muñoz (in memoriam)

Jaime Rodríguez-Arana Muñoz

Jorge Luís Salomoni

José Carlos Abraão
José Eduardo Martins Cardoso
José Luís Said
José Mario Serrate Paz
Juan Pablo Cajarville Peruffo
Juarez Freitas
Julio Rodolfo Comadira
Luís Enrique Chase Plate
Lúcia Valle Figueiredo
Manoel de Oliveira Franco Sobrinho
(in memoriam)
Marçal Justen Filho
Marcelo Figueiredo
Márcio Cammarosano
Maria Cristina Cesar de Oliveira

Nelson Figueiredo

Odilon Borges Junior

Pascual Caiella

Paulo Eduardo Garrido Modesto

Paulo Henrique Blasi

Paulo Neves de Carvalho (in memoriam)

Paulo Ricardo Schier

Pedro Paulo de Almeida Dutra

Regina Maria Macedo Nery Ferrari

Rogério Gesta Leal

Rolando Pantoja Bauzá

Sérgio Ferraz

Valmir Pontes Filho

Yara Stropa

Weida Zancaner

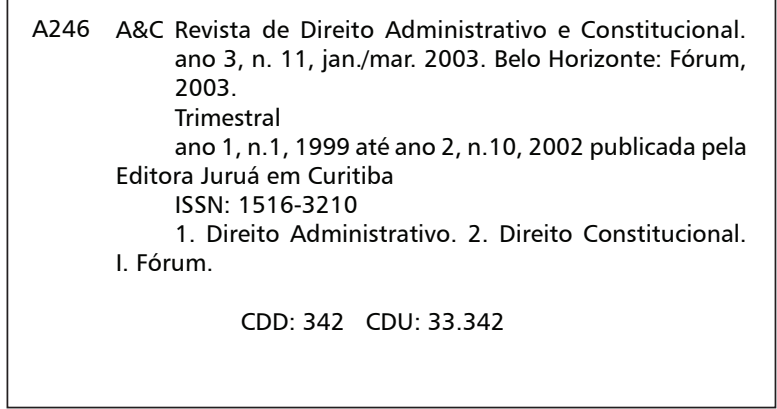

(c) Editora Fórum Ltda. 2008

Todos os direitos reservados. É proibida a reprodução total ou parcial, de qualquer forma ou por qualquer meio eletrônico ou mecânico, inclusive através de processos xerográficos, de fotocópias ou de gravação, sem permissão por escrito do possuidor dos direitos de cópias (Lei $n^{\circ}$ 9.610, de 19.02.1998).

Editora Fórum Ltda.

CEP 30130-007 - Belo Horizonte/MG - Brasil

Tel.: 08007043737

Internet: www.editoraforum.com.br

e-mail: editoraforum@editoraforum.com.br
Av. Afonso Pena, 2770 - 15\%/16 andar - Funcionários

Editor responsável: Luís Cláudio Rodrigues Ferreira

Coordenação editorial: Olga M. A. Sousa

Projeto gráfico e diagramação: Luis Alberto Pimenta

Revisoras: Carolina Rocha

Lourdes Nascimento

Pesquisa jurídica: Fátima Ribeiro - OAB/MG 74868

Bibliotecárias: Fernanda de Paula Moreira

Leila Aparecida Anastácio - CRB 2513 - 6ª região

Os conceitos e opiniões expressas nos trabalhos assinados são de responsabilidade exclusiva de seus autores.

Impressa no Brasil / Printed in Brazil

Distribuída em todo o Território Nacional 


\title{
Una Interpretación Sistémica del Derecho Administrativo Mexicano, de acuerdo con sus Bases Constitucionales
}

\author{
Germán Cisneros Farías \\ Doctor en derecho por la UNAM Miembro del Sistema Nacional de Investigadores, nivel 2 Profesor \\ de teoría del derecho y derecho administrativo, en la Facultad de Derecho y Criminología de la \\ Universidad Autónoma de Nuevo León
}

\begin{abstract}
Palabras clave: Derecho administrativo mexicano. Teoría sistémica del derecho. Interpretación sistémica del derecho. Modelo operativo mexicano

Índice: I Fundamentación teórica - II Elementos esenciales en la teoría sistémica del derecho, aplicables al derecho administrativo - III Interpretación sistémica del derecho administrativo mexicano, de acuerdo con sus bases constitucionales - IV Crítica. Equilibrio y desequilibrio en el modelo operativo mexicano
\end{abstract}

\section{Fundamentación Teórica}

Una de las disciplinas jurídicas en las que es factible aplicar y explicar la teoría sistémica del derecho, es sin duda alguna, el derecho administrativo. ¿Por qué es posible lo anterior? La respuesta es sencilla: el derecho administrativo se refiere sustancialmente a procesos, organización metodológica, Fundamentación interconexiones en las etapas de acción, tiempos de ingreso y salida al sistema, en suma, aplicaciones input,-output, en el detalle reglamentario de aplicar una ley.

Se nos ha dicho que nadie discutiría que esta disciplina jurídica tiene un lugar prominente en la sociedad, ésta, entendida como un sistema omniabarcador de todo lo que sucede socialmente; con tal referencia se establece una delimitación, en opinión de Niklas Lumann. ${ }^{1}$ Conceptos como los de clausura operativa, función, codificación, programación, diferenciación funcional, acoplamiento estructural, autodescripción, evolución - conceptos todos de la teoría de sistemas — podrían ser aplicados a otros ámbitos funcionales de la sociedad moderna, entre ellos a nuestra ciencia.

El derecho ya no se concibe como un de normas aisladas sino como un sistema de operaciones que maneja esquemas propios, insiste Luhmann. Es una poderosa maquinaria de selección y genera una lógica peculiar para dar respuesta a sus problemas en su autopoiesis, se radicaliza, utilizando constante conjunto mente la autoreferencia para trabajar y

${ }^{1}$ Niklas Luhmann, El derecho de la sociedad, Universidad Iberoamericana, México, 2002, p. 58.

A \& C R. de Dir. Administrativo \& Constitucional, Belo Horizonte, ano 8, n. 31, p. 96-123, jan./mar. 2008 
otra vez autoreproducirse. ${ }^{2}$

El derecho se concibe, en su conjunto, como una unidad. A pesar de la inmensa variedad de disposiciones legales que componen todo el orden jurídico, éste debe ser visto como un todo unitario que depende de una esencia vital. El derecho administrativo pertenece a ese orden y está inmerso en el sentido de esa unidad.

Todas las ciencias, incluyendo la jurídica, poseen un conjunto de verdades, principios y leyes internas de permanente verificación. Esas verdades en su conjunto se someten de manera sistemática a una arquitectura científica que nos produce la impresión de un todo perfectamente ordenado, a partir del cual se puede deslindar desde el concepto derecho, hasta sus conceptos conexos, y sobre todo, derivar de dicho orden unitario una interpretación científica interna - ahora sistémica - de cualquier problema, concepto, o institución jurídica, incluyendo por supuesto las normas administrativas.

El derecho en general o alguna de sus ramas, en este caso derecho administrativo, son sistemáticos en la construcción de sus conceptos explicativos externos, y son sistémicos en la aplicación e interpretación de sus estructuras internas.

Expliquémonos.

Los conceptos explicativos externos del derecho están a cargo de la dogmática jurídica. Su función esencial estriba en atrapar una verdad jurídica singular, darle un nombre, construir una nomenclatura afín a esa verdad, de manera tal que esas verdades o instituciones jurídicas constituyan un orden homogéneo, sistemático, armónico, científico.

El carácter sistemático del derecho es - lo repetimos - , fundamentalmente de explicación externa. Entendemos como explicación externa el lenguaje de identificación para esa ciencia y para otras ciencias similares. Es el lenguaje particular de la ciencia. Así, de manera lógica, bajo el principio de identidad, mediante ciertos conceptos lingüísticos se va construyendo el conocimiento explicativo de una ciencia. Pongamos un ejemplo de sistematicidad en las fuentes formales del derecho administrativo. Tal organización se inicia desde las normas específicas referidas a la Constitución, después a sus leyes federales; y de ahí en adelante tienden a la armonía con otras fuentes entre ellas, tratados y convenios

${ }^{2}$ Idem, p. 19

A \& C R. de Dir. Administrativo \& Constitucional, Belo Horizonte, ano 8, n. 31, p. 96-123, jan./mar. 2008 
internacionales; leyes locales; reglamentos; planes y programas; normas oficiales; circulares; acuerdos; decretos; convenios; jurisprudencia; contratos de derecho civil; normas específicas de derecho procesal, mercantil, penal y laboral; principios generales de derecho; costumbre; doctrina. Todo este conjunto normativo constituyen sus fuentes sistemáticas, a las que habrán de referirse de manera inicial cualquier interpretación de un evento administrativo.

Sin embargo, a pesar de la sistematicidad lingüística, — razón comunicativa mediante la cual se concatenan las interacciones y se estructuran las formas de vida, según Habermas ${ }^{3}$ - , para entenderse e interpretarse de manera integral, se recurrirá también a la interpretación sistémica de ese derecho. Éste se refiere a la aplicación y explicación de sus estructuras internas, en la perspectiva de su unidad.

Cualquier unidad científica se percibe como un todo aparentemente homogéneo - ciertamente hacia el exterior —, pero hacia el interior, está compuesto de partes o estructuras básicas que no son fácilmente escindibles la una de las otras. No se pueden literalmente separar. Se pueden explicar — como ahora lo hacemos —, con fines didácticos, metodológicos, hasta ahí. De hacerlo, perderían su característica vital.

Así, la unidad del derecho se convierte en la piedra angular de su existencia. Su pérdida, notable disminución, desvanecimiento gradual desemboca, invariablemente, en el encuentro de otra materia distinta al derecho.

Permítaseme, en este tema, una disgregación que ahora resulta pertinente. El derecho, bajo la presión social de regular las diferentes mutaciones de la vida cotidiana, se va atomizando sin control alguno - y a esto no es ajeno el derecho administrativo - en ramas, subdivisiones, parcelas de su mismo contenido, hasta arribar al límite de lo artificial. Esta inercia amenaza con romper de manera abrupta sus dos eslabones científicos: unidad en su contenido esencial y sistematicidad en los productos diversos de ese mismo contenido.

La dinámica social sigue su curso. Las parcelas del derecho administrativo seguirán creciendo. Debemos construir una aceptable teoría sistémica del derecho, para que las futuras ramificaciones se den sin la zozobra de un rompimiento peligroso que convierta en ineficaz a esta disciplina.

Retomemos el tema.

3 Jürgen Habermas, Facticidad y validez, trotta, Madrid, 1998, p. 65.

A \& C R. de Dir. Administrativo \& Constitucional, Belo Horizonte, ano 8, n. 31, p. 96-123, jan./mar. 2008 


\section{Elementos esenciales en la teoría sistémica del derecho, aplicables al derecho administrativo}

La teoría sistémica del derecho, como paradigma, ${ }^{4}$ tiene una estructura básica, compuesta por ciertos elementos y, a partir de ellos, se puede explicar y aplicar el derecho en general.

¿Cuáles son los elementos esenciales en la teoría sistémica del derecho, aplicables también al derecho administrativo?

Daremos la respuesta en forma esquemática. No es este el momento para ampliar una explicación de suyo compleja. Habremos de referirnos a los puntos estructurales de la teoría sistémica del derecho.

Estos se refieren a la filosofía, lógica, metodología y teorética, sustantivos que deben calificarse con el agregado de: jurídica. Así, en la preocupación central de la filosofía jurídica encontraremos a la justicia como su principal y única preocupación a despejar. Concebimos a la justicia como un estado espiritual de gracia, ausencia de transgresiones, que al colocarse el hombre en estado opuesto a ella se recurre al derecho para reconciliarlo con su estado original. Los conceptos de justicia y Estado, justicia y derecho administrativo cruzan por la primera ocupación de la teoría sistémica del derecho.

En la lógica jurídica buscaremos, además de sus grandes principios de identidad, no contradicción, tercero excluso, razón suficiente y causalidad jurídica, los argumentos que hagan racional la aplicación de una norma administrativa. Buscaremos también el sentido común, tanto expreso como implícito, en una norma. Con la metodología jurídica encontraremos modos, tiempos, procesos, etapas, movimientos, en fin, actividades reglamentarias armónicas en la ejecución o eficacia de una ley de jerarquía superior. No olvidemos la afirmación de Carnelutti ${ }^{5}$ de que el derecho es un orden - una organización, un método-, pero ético. En la teorética jurídica conjugaremos una tesis, doctrina totalizadora, criterio científico global, en suma, el punto de vista unitario que une cada uno de los eslabones teóricos arriba mencionados.

Las anteriores son las estructuras internas-diríamos en un lenguaje

\footnotetext{
4 Al decir de Kuhn, un nuevo paradigma implica una definición de trabajo. Unirse, aislarse o permanecer en el grupo anterior, tales son las consecuencias. Thomas $\mathrm{S}$. Kuhn, la estructura de las revoluciones científicas, fondo de cultura económica, México, 1982, p. 46.

5 Francesco Carnelutti, Metodología del Derecho, traducción Ángel Osorio, Uteha, México 1962, p. 12.
} 
eminentemente lógico —, necesarias en su sentido apodíctico, para aplicar y explicar el derecho administrativo.

Sin embargo, el derecho explicado como teoría sistémica, posee dos elementos de enlace hacia el universo sistemático del derecho mismo, sin los cuales no puede convertirse en eficaz, pues quedaría como una mera abstracción teórica. El derecho se vive, se aplica, sirve para retomar el sentido de la justicia humana, no es una fórmula lógica, abstracta, sin sentido fenomenológico. No es una entelequia, un mero silogismo. Es un hecho. Por tal razón posee dos elementos externos: una llave de ingreso y una respuesta de salida.

El in put del derecho está referido a una petición formal, y el out put está referido a la sentencia definitiva, a la cosa juzgada. En ambos casos interviene el derecho administrativo para darle eficacia a todo el orden jurídico.

La audiencia aquí presente, se estará formulando una pregunta: en qué momento abordará el ponente el tema del derecho administrativo.

Contesto: ya lo estoy abordando. ¿Acaso en el derecho administrativo está ausente el tema de la justicia? Por supuesto que no. Administrar en su sentido público significa distribuir, dar a cada quien lo suyo, jus cuique tribuendi, tratar igual a los desiguales, tener un sentido de equidad en la distribución de una carga o de un beneficio.

Pretendo, en las páginas subsecuentes, demostrar que el derecho administrativo puede explicarse y aplicarse, a partir de la teoría sistémica del derecho tomando como base las normas constitucionales de un país, en este caso, el Estado mexicano.

III Interpretación sistémica del derecho administrativo mexicano, de acuerdo con sus bases constitucionales

\section{A) Filosofía jurídica en el derecho administrativo}

Toda Constitución, y en particular la del país de Anáhuac, responde a dos preguntas fundamentales: ¿Qué derechos se constituyen como pacto mínimo o esencial?, y, ¿Cómo habremos de hacer funcionar esos derechos? Daremos oportuna respuesta a tales inquisiciones, aunque aceptamos la tesis de Häberle ${ }^{6}$ de que: frente a este trasfondo debe concebirse a la Constitución como un estadio cultural. Toda Constitución de un Estado constitucional vive en última instancia de la dimensión de lo cultural. La

A \& C R. de Dir. Administrativo \& Constitucional, Belo Horizonte, ano 8, n. 31, p. 96-123, jan./mar. 2008 
protección de los bienes culturales, las libertades culturales especiales, las cláusulas expresas sobre el patrimonio cultural y los artículos generales sobre el Estado de cultura no constituyen sino las manifestaciones particulares de la dimensión cultural de ella.

La respuesta a la segunda de esas inquietudes le corresponde, de manera preponderante, convertirla en eficaz — ciertamente al Poder Ejecutivo -, pero en particular le atañe al derecho administrativo. Empero, tal eficacia se encuentra amarrada, atada al contenido de la primera de esas preguntas. Es entonces necesario establecer no tan sólo el continente — derecho administrativo - , sino el contenido de los derechos mínimos o esenciales que habrá de conducir, administrar nuestra materia jurídica.

El derecho administrativo no es tan sólo un método, una argumentación lógica, una forma de funcionamiento, una maquinaria virtual sin contenido alguno. Sirve ciertamente para conducir, para hacer llegar algo, pero también posee filtros para detectar que lo conducido o ese algo, tenga, pertenezca o posea la sustancia mínima de justicia, de equidad, de valor, de bien cultural, en suma de la unidad básica del derecho. Desde esta perspectiva, responde a una base filosófica que habrá de encontrar en los derechos fundamentales del hombre y en los derechos sociales — contenido mínimo a administrar - desde los cuales se hace la primera interpretación del derecho en general, y en este caso, del derecho administrativo.

Las bases constitucionales del derecho administrativo mexicano que en el transcurso de este trabajo señalaremos, toman los contenidos fundamentales a distribuir, de dos grandes apartados. ${ }^{7}$ De manera inicial, del título primero de dicha Constitución (sin título expreso ), capítulos I, II, III y IV que se refieren respectivamente, de las garantías individuales, de los mexicanos, de los extranjeros, y de los ciudadanos mexicanos. Apuntamos que el título expreso debiera referirse a: título primero, de los derechos fundamentales del hombre. Sólo así pudiera entenderse nuestra posición de que el derecho administrativo mexicano administre - respeta la sustancia, condiciones, excepciones, prohibiciones y requisitos-de la justicia contenida en los derechos del hombre relativos a:

a. $1^{\circ}$ ) libertad y dignidad; b. $2^{\circ}$ ) libre determinación a las comunidades indígenas; c. $\left.3^{\circ}\right)$ educación universal; d.4) igualdad del varón y la mujer, protección de la salud, vivienda digna, dignidad de la niñez; e.5) libertad de trabajo; f.6) manifestación de las ideas; g.7) libertad de expresión; h.8) ejercicio de petición; i.9) asociación pacífica; j.10) posesión de armas en su domicilio; k.11) libertad de

6 Peter Häberle, El Estado constitucional, UNAM, México, 2003, p. 5.

${ }^{7}$ Constitución política de los estados unidos mexicanos, 151 ava. Edición, editorial Porrúa, México, 2006. 
tránsito; 1.12) igualdad por calificación de sangre; m.13) prohibición de leyes o tribunales especiales; n. 14) debido proceso, seguridad jurídica integral; o.15) prohibición de la extradición contraria a la libertad; p.16) principio de legalidad exigible a la autoridad competente; q.17) judicialización gratuita, independiente y plena; r.18) nulum delictum sine poene sine lege; s.19) auto de formal prisión; requisitos; t.20) garantías procesales del inculpado; u.21) competencia separada en penas, investigación y persecución de los delitos; competencia para infracciones reglamentarias; competencia concurrente en seguridad pública; competencia y funciones en el sistema nacional de seguridad pública; v. 22) prohibición de penas inusitadas y trascendentales; w.23) non bis idem; x.24) libertad religiosa; y.25) rectoría del Estado en desarrollo nacional; z.26) planeación democrática del Estado federal democrático; alfa.27) declaración del origen de propiedad de tierras y aguas; propiedad privada; modalidades de la propiedad privada según el interés público; el Estado y el dominio directo de los recursos naturales entre ellos petróleo, gas, energéticos y telecomunicaciones; beta.28) prohibición de monopolios, casos de excepción de monopolios; gamma29 ) suspensión de las garantías públicas; delta.30) nacionalidad mexicana; épsilon.31) obligaciones de los mexicanos; obligación de contribuciones fiscales; dseta.32) conflictos de nacionalidad; eta.33) derecho de los extranjeros a las garantías constitucionales; excepciones de libertad y políticas a los extranjeros; zeta.34) requisitos de ciudadanía; iota.35) prerrogativas del ciudadano; kappa.36) obligaciones ciudadanas; lambda.37) pérdida de la ciudadanía mexicana; mi.38) suspensión de derechos constitucionales.

Y toma de un segundo apartado, los derechos sociales del hombre tutelado por el Estado - concepto doctrinal propuesto y construido por la Constitución mexicana de 1917 - que se encuentran establecidos en los artículos constitucionales $3^{\circ}, 27,39,123$ y 130.

En el artículo $3^{\circ}$ concibe el concepto de Estado educador; la autonomía universitaria en funciones sustantivas de docencia, investigación y difusión de su universo cultural. En el artículo 27 acuña el concepto de propiedad de origen, a favor del Estado, de tierras, aguas petróleo, gas, combustibles sólidos, energía eléctrica y las telecomunicaciones. En los artículos 39 y 130 presenta su propuesta de soberanía de origen, para darse un modelo operativo con el carácter de soberano, de otro u otros modelos. En el artículo 123 define y da las bases para la seguridad social, mediante el derecho al acceso al trabajo digno y socialmente útil.

De estos derechos fundamentales del hombre y de los derechos sociales tutelados por el Estado irradia la filosofía jurídica que alumbra la aplicación del derecho administrativo mexicano como sistema. Bajo esa luz, ahora guiada por el principio de identidad lógica, emanan las normas jurídicas principales, se emiten las disposiciones reglamentarias, se aplica e interpreta todo el orden jurídico nacional. 


\section{B) La llave de ingreso y salida al sistema jurídico en general, y en par- ticular, al derecho administrativo como sistema}

El ingreso al ejercicio de todo el orden jurídico mexicano, de manera general, se realiza a través del artículo $8^{\circ}$ constitucional; sin embargo, el ingreso particular a cada uno de los órganos o poderes que constituyen su propio sistema - legislativo, judicial, ejecutivo - se efectúa de manera específica, en el contexto del artículo mencionado. Iniciativa para la legislación, denuncia o querella para el judicial, solicitud para el ejecutivo. La queja es la llave de ingreso a la protección de los derechos humanos tanto constitucionales como de todo el orden jurídico mexicano.

En tanto, la clausura del orden jurídico mexicano se da también bajo el principio del artículo $8^{\circ}$ constitucional, bajo el concepto de acuerdo o respuesta dada en breve término al peticionario. Empero la salida en cada Poder u órgano estatal, se otorga mediante diferentes figuras jurídicas: publicación para la iniciativa del proceso legislativo; sentencia definitiva para el proceso judicial y acuerdo para el proceso administrativo.

Como sistema, el derecho administrativo tiene una base constitucional de ingreso a dicho sistema, en este caso nos referimos al artículo $8^{\circ}$ de la constitución que se refiere al ejercicio del derecho de petición al que están obligados a responder los funcionarios y empleados públicos, con un acuerdo escrito y dado a conocer en breve término al peticionario. Esta última parte constituye la etapa de salida en el sistema jurídico en general.

El ejercicio de este derecho, de esta condición de ingreso al sistema jurídico, se hará por escrito, de manera pacífica y respetuosa ante tal funcionario o empleado público, constituyendo con ello la llamada petición o solicitud administrativa. La salida obedece a la misma formalidad.

Ya hemos dado respuesta a la primera pregunta, y hecho también la observación de que, el ingreso al ejercicio de tales contenidos constitucionales se efectúa mediante el derecho de petición.

\section{C) La organización lógica del orden jurídico, del derecho administrativo y del modelo operativo}

Hemos afirmado, que el derecho administrativo como sistema, encuentra la debida fundamentación filosófica de los contenidos a administrar, en la parte primera de toda Constitución, que por lo general, constituyen los derechos mínimos esenciales de la población pactante; pero, ¿̇ómo habrán de hacerse funcionar tales derechos? A partir de esta respuesta, se 
inicia la organización lógica del orden jurídico en general y en particular del derecho administrativo.

Esta parte lógica está referida al encuentro del modelo operativo y su funcionamiento. Nos referimos al Estado y su forma de gobierno.

En el pacto constitucional, además de los derechos fundamentales, los entes constitutivos del mismo acuerdan el modelo operativo, en su máxima categoría, para hacer funcionar tales derechos. No inventan - aunque pueden hacerlo - un modelo, lo toman de la experiencia cultural. Este modelo puede ser, en palabras de Nicolás Maquiavelo: tutti domini che hanno avuto ed hanno imperio sopra li uomini, sono stati... sono reppubliche o principati. Estado, República o principado son los modelos operativos, - repetimos - en su máxima categoría, que pueden acordarse en un pacto constitutivo.

En el caso mexicano tenemos al Estado Federal como respuesta a esta inquietud, según se lee en el artículo 40 constitucional.

En la perspectiva de nuestra tesis el Estado es una unidad de fin. La existencia de tal fin o fines resulta del hecho psicológico, irrefutable, de consistir la vida del Estado en una serie ininterrumpida de acciones humanas, y como toda acción es necesariamente determinada por un motivo, toda acción es a su vez determinada por un fin. La eliminación de toda finalidad, respecto del Estado en el sentido que hemos dicho, le degradaría hasta hacer de él una fuerza ciega y natural, le robaría toda unidad y continuidad, lo que sólo puede ser hijo o de la falta de claridad o de la ausencia de todo pensamiento.

Por esto la doctrina social del Estado al partir de una concepción de esta naturaleza acerca del mismo, ha de probar cuáles son los fines que elevan a unidad la variedad que se halla reunida en el Estado. Toda ley, toda disposición, todo nombramiento, todo contrato entre Estados, incluyendo el derecho administrativo necesita tener un fin, y un fin conforme a la conciencia de sus autores; es decir, un fin racional, o en caso contrario el Estado no sería sino, efectivamente una aglomeración de hombres - pero irracionales —, una aglomeración de locos, esto es, un gran manicomio.

Como ley pública, el derecho administrativo tiene estructura y fines que se sustentan en una base constitucional. Estas bases constitucionales se acomodan al perfil del Estado al cual sirven.

En este contexto formulemos las siguientes aporías: ¿cuál es la base constitucional para definir el Estado mexicano? ¿A qué clase de Estado se refiere la base constitucional relativa? Y dadas esas respuestas, hagamos

A \& C R. de Dir. Administrativo \& Constitucional, Belo Horizonte, ano 8, n. 31, p. 96-123, jan./mar. 2008 
la siguiente inquisición: ¿hay correspondencia entre la definición dada a la clase de Estado mexicano, según su base constitucional, y la forma de gobierno administrativo, de acuerdo con sus normas constitucionales, o se trata de dos sistemas distintos?

Iniciemos nuestro estudio.

La respuesta dada por el artículo 40 constitucional — Estado Federal - penetra en las diversas entidades federativas y municipios, de manera tal que sus características de organización constitucional están presentes en ellas, así se indica en los artículos 41, 49 párrafo primero, 102 párrafo primero, 115 párrafo primero, 116 párrafos primero y segundo y 119 párrafo segundo.

Se lee en los artículos citados.

Artículo 40.-Es voluntad del pueblo mexicano constituirse en una República representativa, democrática, federal, compuesta de Estados libres y soberanos en todo lo concerniente a su régimen interior; pero unidos en una federación establecida según los principios de esta ley fundamental.

Artículo 41.-El pueblo ejerce su soberanía por medio de los Poderes de la Unión, en los casos de la competencia de éstos, y por los de los Estados, en lo que toca a sus regímenes interiores, en los términos respectivamente establecidos por la presente Constitución Federal y las particulares de los Estados, las que en ningún caso podrán contravenir las estipulaciones del Pacto Federal.

Artículo 49.-El Supremo Poder de la Federación se divide, para su ejercicio, en Legislativo, Ejecutivo y Judicial.

Artículo 102.-(...) El Ministerio Público de la Federación estará presidido por un Procurador General de la República, designado por el titular del Ejecutivo Federal con ratificación del Senado o, en sus recesos de la Comisión Permanente. (...)

B. El Congreso de la Unión y las legislaturas de las entidades federativas, en el ámbito de sus respectivas competencias, establecerán organismos de protección de los derechos humanos que ampara el orden jurídico mexicano, los que conocerán de quejas en contra de actos u omisiones de naturaleza administrativa provenientes de cualquier autoridad o servidor público, con excepción de los del Poder Judicial de la Federación, que violen estos derechos.

Artículo 115.-Los Estados adoptarán, para su régimen interior, la forma de gobierno republicano, representativo, popular, teniendo como base de su división territorial y de su organización política y administrativa, el Municipio Libre.

Artículo 116.-El poder público de los Estados se dividirá, para su ejercicio, en Ejecutivo, Legislativo y Judicial, y no podrán reunirse dos o más de estos poderes en una sola persona o corporación, ni depositarse el legislativo en un solo individuo.

Los Poderes de los Estados se organizarán conforme a la Constitución de cada uno de ellos,.....

Artículo 119.-(...) Cada Estado y el Distrito Federal están obligados a entregar sin demora a los indiciados, procesados o sentenciados, así como a practicar el aseguramiento y entrega de objetos, instrumentos o productos del delito, 
atendiendo a la autoridad de cualquier otra entidad federativa que los requiera. Estas diligencias se practicarán, con intervención de las respectivas procuradurías generales de justicia, en los términos de los convenios de colaboración que, al efecto, celebren las entidades federativas. Para los mismos fines, los Estados y el Distrito Federal podrán celebrar convenios de colaboración con el Gobierno Federal, quien actuará a través de la Procuraduría General de la República.

\section{C.1 La organización lógica del modelo operativo y sus órganos para darle eficacia al orden jurídico. El Estado federal}

Hemos dicho que la organización constitucional establecida por los artículos arriba mencionados, penetra y se asienta como forma de gobierno en la república de Anáhuac. Efectivamente, el modelo histórico de gobierno - legislativo, ejecutivo y judicial — propuesto por John Locke, ajustado por Montesquieu, establecido por vez primera en la constitución estadual de Virginia en 1776, y de manera definitiva, en la Constitución de los Estados Unidos de América, en 1787, es la estructura básica de gobierno en el Estado federal mexicano y en las entidades federativas de ese país.

Bajo los principios de identidad y de no contradicción en las citadas normas constitucionales se da la armonía necesaria para afirmar que estamos ante un Estado federal y entidades federales que responden a un modelo de Estado políticamente descentralizado, pues tal como la doctrina lo señala no existe una sola idea de Estado federal en la Constitución mexicana sino que hay Estados federales, cuyas decisiones políticas son coincidentes, es decir hay dos conceptos de Estado en una coincidencia constitucional, con dos formas administrativas convergentes. En tanto el Estado federal se administra bajo un concepto central, el otro Estado federativo tiene una descentralización política con facultades de decisión política en determinada competencia territorial. En este aspecto hay que señalar la supremacía del Estado federal, del todo, sobre cualquiera de las partes, para conservar el principio de unidad.

Así, en la asunción y ejercicio de las competencias que le son propias al Estado federal y en la asunción y ejercicio de las competencias — coincidentes - que le son propias a las Entidades federativas - incluyendo al municipio - , se realizan todas las funciones del Estado mexicano por conducto del derecho administrativo, de una manera enteramente lógica.

Se dan entonces en la Constitución tres ámbitos de competencia parciales, dentro de un concepto total de competencia a favor del Estado mexicano. El primer ámbito de competencia se da a un universo expreso a favor del Estado federal, otro bajo un criterio residual en beneficio de 
las entidades federativas, y un tercer ámbito de competencia se otorga de manera expresa a favor del municipio.

La asunción y ejercicio de las competencias mencionadas - Estado federal y entidades federativas y municípios - se inician con la interpretación de una norma constitucional que la doctrina ha denominado: criterio residual.

Las facultades que no están expresamente concedidas por esta Constitución a los funcionarios federales (diputados, senadores, presidente de la república, procurador general de la república, secretarios del despacho, ministros de la Suprema Corte de Justicia, magistrados y jueces federales), se entienden reservadas a los Estados, dice el artículo 124 constitucional.

La interpretación lógica de este precepto, llamado precepto de criterio residual, se refiere a que las facultades de los funcionarios federales se encuentran expresamente consignadas en la Constitución, en caso contrario - criterio residual —, se entienden reservadas a favor de las entidades federativas. Por ello, consignaremos aquí el universo expreso a favor del Estado federal. El otro universo no expreso se da a las entidades federativas, y en ese universo no expreso se da contenido a la tridimensionalidad de la forma de gobierno, consignada en los artículos 41, párrafo primero y 115 párrafo primero.

El modelo operativo tiene funciones de competencia lógicas para cada uno de sus órganos. La suma de ellas, conservando su unidad lógica, da el universo de competencias a favor del Estado federal.

Este apartado de competencias tiene señalada importancia en el derecho administrativo, pues a partir de ellas, el Estado ahora organizado de manera metodológica, establecerá una serie de disposiciones administrativas para hacer funcionar todo el orden jurídico.

Señalaremos las competencias más importantes de cada uno de los órganos de ese modelo operativo - legislativo, judicial, ejecutivo - mencionando la base constitucional de cada una de ellas.

\section{C.1.a Competencia del Congreso de la Unión}

El Poder Legislativo Federal tiene facultades políticas y legislativas per se Las facultades políticas se distribuyen de manera metodológica con el carácter de exclusivas, algunas para la Cámara de Diputados, otras para la Cámara de Senadores, y las demás de manera indistinta bajo la denominación de Congreso de la Unión. Las facultades legislativas se dan en su conjunto al Congreso de la Unión y a partir de ellas, de la emisión de una 
norma legislativa, se inicia el funcionamiento del derecho administrativo.

El Congreso de la Unión tiene las siguientes facultades:

1. Para imponer las contribuciones necesarias a cubrir el presupuesto;

2. Para legislar en toda la República sobre hidrocarburos, minería, industria cinematográfica, comercio, juegos con apuestas y sorteos, intermediación y servicios financieros, energía eléctrica y nuclear, y para expedir las leyes del trabajo;

3. Para dictar leyes sobre nacionalidad, condición jurídica de los extranjeros, ciudadanía, naturalización, colonización, emigración e inmigración y salubridad general de la República;

4. Para dictar leyes sobre vías generales de comunicación y sobre postas y correos; para expedir leyes sobre el uso y aprovechamiento de las aguas de jurisdicción federal;

5. Para establecer casas de moneda, fijar las condiciones que ésta deba tener, dictar reglas para determinar el valor relativo de la moneda extranjera y adoptar un sistema general de pesas y medidas;

6. Para expedir las leyes de organización del Cuerpo Diplomático y el Cuerpo Consular mexicanos;

7. Para establecer los delitos y faltas contra la Federación y fijar los castigos que por ellos deban imponerse.

8. Para expedir leyes que establezcan las bases de coordinación entre la Federación, el Distrito Federal, los Estado y los Municipios, en materia de seguridad pública; así como para la organización y funcionamiento, el ingreso, selección, promoción y reconocimiento de los integrantes de las instituciones de seguridad pública en el ámbito federal;

9. Para expedir la Ley que regule la organización de la entidad de fiscalización superior de la Federación y las demás que normen la gestión, control y evaluación de los Poderes de la Unión y de los entes públicos federales;

10. Para establecer, organizar y sostener en toda la República escuelas rurales, elementales, superiores, secundarias y profesionales; de investigación científica, de bellas artes y de enseñanza técnica; escuelas prácticas de agricultura y de minería, de artes y oficios, museos, bibliotecas, observatorios y demás institutos concernientes a la cultura general de los habitantes de la Nación y legislar en todo lo que se refiere a dichas instituciones; para legislar sobre vestigios o restos fósiles y sobre monumentos arqueológicos, artísticos

A \& C R. de Dir. Administrativo \& Constitucional, Belo Horizonte, ano 8, n. 31, p. 96-123, jan./mar. 2008 
e históricos, cuya conservación sea de interés nacional; así como para dictar las leyes encaminadas a distribuir convenientemente entre la Federación, los Estados y los Municipios el ejercicio de la función educativa y las aportaciones económicas correspondientes a ese servicio público, buscando unificar y coordinar la educación en toda la República. Los títulos que se expidan por los establecimientos de que se trata surtirán sus efectos en toda la República;

11. Para establecer contribuciones: sobre comercio exterior, recursos naturales, instituciones de crédito y seguros, energía eléctrica, tabacos, gasolina, explotación forestal y cerveza, tanto en la producción como en el consumo;

12. Para legislar sobre las características y uso de la bandera, escudo e himno nacionales;

13. Para expedir las leyes que establezcan la concurrencia del Gobierno Federal, de los Estados y de los Municipios, en el ámbito de sus respectivas competencias, en materia de asentamientos humanos;

14. Para expedir leyes sobre planeación nacional del desarrollo económico y social;

15. Para expedir leyes para la programación, promoción, concertación y ejecución de acciones de orden económico, especialmente las referentes al abasto y otras que tengan como fin la producción suficiente y oportuna de bienes y servicios, social y nacionalmente necesarios;

16. Para expedir leyes tendientes a la promoción de la inversión mexicana, la regulación de la inversión extranjera, la transferencia de tecnología y la generación, difusión y aplicación de los conocimientos científicos y tecnológicos que requiere el desarrollo nacional;

17. Para expedir leyes que establezcan la concurrencia del Gobierno Federal, de los Gobiernos de los Estados y de los Municipios, en el ámbito de sus respectivas competencias, en materia de protección al ambiente y de preservación y restauración del equilibrio ecológico;

18. Para expedir leyes que instituyan tribunales de lo contencioso-administrativo, dotados de plena autonomía para dictar sus fallos, y que tengan a su cargo dirimir las controversias que se susciten entre la administración pública federal y los particulares, estableciendo las normas para su organización, su funcionamiento, el 
procedimiento y los recursos contra sus resoluciones;

19. Para expedir leyes que establezcan las bases sobre las cuales la Federación, los Estados, el Distrito Federal y Municipios; coordinarán sus acciones en materia de protección civil;

20. Para legislar en materia de deporte, estableciendo las bases generales de coordinación de la facultad concurrente entre la Federación, los Estados, el Distrito Federal y Municipios; asimismo de la participación de los sectores social y privado;

21. Para expedir leyes en materia de turismo, estableciendo las bases generales de coordinación de las facultades concurrentes entre la Federación, Estados Municipios y el Distrito Federal, así como la participación de los sectores social y privado;

22. Para expedir leyes que establezcan la concurrencia del Gobierno Federal, de los Gobiernos de las Entidades Federativas y de los Municipios, en el ámbito de sus respectivas competencias, en materia de pesca y acuacultura, así como la participación de los sectores social y privado;

23. Para expedir leyes en materia de seguridad nacional, estableciendo los requisitos y límites a las investigaciones correspondientes, y

24. Para expedir todas las leyes que sean necesarias, a objeto de hacer efectivas las facultades anteriores y todas las otras concedidas por esta Constitución a los Poderes de la Unión.

\section{C.1.b Competencia del Poder Judicial}

La competencia del Poder Judicial se encuentra señalada en los artículos 103, 104, 105, 106, 107 de la Constitución y tienen funciones jurisdiccionales plenas en todo el territorio nacional sobre la violación de los derechos humanos, la invasión de competencias entre autoridades estatales; así como el conocimiento de la materia propiamente federal y de la revisión en las resoluciones definitivas de los tribunales de lo contencioso administrativo.

El Poder Judicial tiene como cúspide a la Suprema Corte de Justicia de la Nación encargada de dar coherencia a todo el orden jurídico, mediante el conocimiento de las controversias constitucionales o acciones de inconstitucionalidad que se susciten entre los tres órganos de gobierno mencionados, según se den las variables especificadas en el artículo 105 constitucional.

A \& C R. de Dir. Administrativo \& Constitucional, Belo Horizonte, ano 8, n. 31, p. 96-123, jan./mar. 2008 
La respuesta dada por el Poder Judicial la tomaremos como la clausura del derecho como sistema jurídico. Aspecto que veremos más adelante.

\section{C.1.c Competencia del Poder Ejecutivo. Su aspecto lógico dentro del modelo operativo}

Nadie duda de la singular importancia que tiene el estudio del Poder Ejecutivo dentro del Derecho administrativo en general. Tratadistas hay que asimilan e identifican dichos conceptos. Aquí haremos un deslinde de dicho órgano, desde dos puntos de vista. Lógico el primero y metodológico el segundo.

En el aspecto lógico referido al órgano del Poder Ejecutivo en el modelo operativo, el Poder señalado tiene las siguientes competencias: al interior, promulga y publica una ley, organiza internamente la forma de cumplirla; y se presenta al exterior como el representante del orden jurídico.

Tales competencias las toma de los artículos 89 fracción I 90 y de la fracción X del artículo 89 mencionado.

Establecidas esas funciones lógicas, como órgano del modelo operativo, a partir de ahí se inician todas sus funciones metodológicas que dan cabida de manera plena al derecho administrativo. De cierto modo, los tratadistas tienen razón al afirmar que hay una fuerte identidad en los conceptos Poder Ejecutivo y derecho administrativo, pues no se puede concebir el uno sin el otro.

Sin embargo, para conseguir una interpretación sistémica del derecho administrativo, debemos puntualizar todos y cada uno de los aspectos metodológicos del Poder Ejecutivo para encuadrarlos tanto en la fundamentación filosófica mencionada como en la argumentación lógica de sus competencias y en la adecuación particular de su eficacia en el orden jurídico.

\section{D) La organización metodológica del modelo operativo federal. Poder ejecutivo presidencialista. Derecho administrativo}

En el esquema teórico se ha dejado al órgano ejecutivo el estudio relacionado con la eficacia del orden jurídico. A él le corresponde cerrar la operación total del sistema jurídico. Esta operación de clausura la hará mediante una serie de disposiciones administrativas, (en caso de revisión o duda se traslada para esta etapa al órgano judicial), y dada la respuesta definitiva, directa o revisada, habrá de llegar finalmente al órgano ejecutivo 
para el cierre de la operación del sistema. Corresponde entonces al Ejecutivo dictar una serie de medidas legales para hacer funcionar la cosa pública.

Esta circunstancia nos permite afirmar que la forma de gobierno en el Estado federal mexicano, es presidencialista, según se lee en los artículos 80, 89, 90 y 92 de la Constitución. En el 80 se lee: se deposita el ejercicio del Supremo Poder Ejecutivo de la Unión en un solo individuo que se denominará "Presidente de los Estados Unidos Mexicanos

Establecido constitucionalmente - dentro del modelo operativo ya señalado - , el sistema o régimen presidencialista, a partir de ahí se dan una serie de disposiciones metodológicas en ese sentido para establecer la eficacia de todo el orden jurídico mexicano.

El presidente de la República, tal como hemos arriba mencionado: promulga y ejecuta las leyes que expida el Congreso de la Unión, proveyendo en la esfera administrativa a su exacta observancia. (Artículo 89, fracción I). Efectuado lo anterior, inicia la organización metodológica del orden jurídico, según se lo ordena el artículo 90, en los siguientes términos: la Administración Pública Federal será centralizada y paraestatal conforme a la Ley Orgánica que expida el Congreso, que distribuirá los negocios del orden administrativo de la Federación que estarán a cargo de las Secretaría de Estado y Departamentos Administrativos y definirá las bases generales de la creación del Ejecutivo Federal en su operación.

Y le establece como método, para la eficacia y seguridad de tal orden, el llamado refrendo ministerial: artículo 92.-Todos los reglamentos, decretos, acuerdos y órdenes del Presidente deberán estar firmados por el Secretario de Estado o Jefe del Departamento Administrativo a que el asunto corresponda, y sin este requisito no serán obedecidos.

Como hemos visto, el orden jurídico tiene una cara hacia el interior de ese orden, y presencia hacia el exterior. Tales aspectos son cubiertos por facultades constitucionales dadas al presidente de la República. Así, el presidente de la república es jefe de estado (Estados Unidos Mexicanos) y jefe de gobierno (poder público de la federación).

En nuestro sistema de gobierno es difícil dividir las facultades del presidente en una y otra clase. Ya vimos que en los regímenes en que existe un jefe de gobierno distinto del jefe estado, a éste le corresponde la ejecución de actos meramente protocolarios y de representación.

Junto a esas tareas protocolarias, tendrá como jefe de estado la conducción de las relaciones con los demás poderes, entre otras. Ensayemos 
una clasificación de las facultades metodológicas que el art. 89 de la constitución le otorga al presidente.

En su carácter de jefe del modelo operativo.

1. Ejecutar las leyes que expida el congreso de la unión y reglamentarlas para su exacta observancia.

2. Nombrar y remover libremente a los secretarios del despacho, al procurador general de la república (en este caso con la aprobación del senado), y aprobar la remoción del procurador de justicia del Distrito Federal, remover a los agentes diplomáticos y empleados superiores de hacienda y nombrar y remover libremente a los demás empleados federales, cuyo nombramiento o remoción no esté determinado de otro modo en la carta magna o en las leyes.

3. Nombrar a los ministros, agentes diplomáticos y cónsules generales, con aprobación del senado o de la comisión permanente.

4. Nombrar, con aprobación del senado o de la comisión permanente, a los coroneles y otros oficiales superiores del ejército, armada y fuerza aérea y altos funcionarios de hacienda.

5. Nombrar a los demás oficiales del ejército, armada y fuerza aérea con arreglo a las leyes.

6. Disponer de la totalidad de la fuerza armada permanente, o sea del ejército terrestre, de la marina de guerra y de la fuerza aérea, para la seguridad interior y defensa exterior de la federación.

7. Disponer de la guardia nacional para los mismos objetivos, en los términos que previene la fracc. IV del art. 76 de la constitución.

8. Dirigir la política exterior y celebrar tratados internacionales, sometiéndolos a la aprobación del senado.

9. Facilitar al poder judicial los auxilios que necesite para el ejercicio expedito de sus funciones.

10. Habilitar toda clase de puestos, establecer adunas marítimas y fronterizas y fijar su ubicación.

A partir de esas facultades constitucionales, el Poder Ejecutivo se organiza, crea organismos — inicia la creación del derecho administrativo - para dar eficacia al orden jurídico mediante la operación de su propio sistema llamado administración pública federal o local, según el caso.

Así, el Poder Ejecutivo, como órgano del modelo operativo, crea organismos subordinados.

Con base en los preceptos constitucionales que a continuación se men- 
cionan, establece los siguientes: a) Secretarías de Estado, b) departamentos administrativos, c) procuradurías de justicia. Esa misma organización se establece en las entidades federativas.

Establecida la forma de organización administrativa, en este caso centralizada y paraestatal, debemos resaltar la importancia dentro de nuestra teoría de tres aspectos metodológicos relacionados con la eficacia del orden jurídico desde la perspectiva del derecho administrativo, que se otorgan al titular del Poder Ejecutivo.

Tales aspectos se refieren a la promulgación de una ley, el refrendo ministerial que es su confirmación como evento de perfección de todo acto administrativo, y el acto coercitivo público.

Ya hemos dicho que el primer aspecto metodológico para la eficacia plena del orden jurídico se inicia con la promulgación de una ley emanada del Poder Legislativo. En efecto, tal Poder publica y ejecuta las normas jurídicas. La facultad de ejecutarla es la función natural de ese Poder, pero para ello requiere de una instancia administrativa especial denominada Procuraduría de Justicia, artículo 102 constitucional, investida de facultades constitucionales para perseguir delitos y llevar ante los tribunales a los inculpados. Dada la respuesta definitiva del orden jurisdiccional, el Estado a través de la administración pública lleva a su etapa final la eficacia de una ley. Aquí, con este evento, se cierra el sistema administrativo público.

El segundo aspecto metodológico relativo a la eficacia se relaciona con el refrendo. Este aparece como base constitucional en el artículo 92 ya citado. Ahora sí, promulgada una ley y establecida la competencia a favor de la Procuraduría General de Justicia, tomamos nota de los siguientes preceptos constitucionales - que organizados metodológicamente en un orden jurídico - permitirán el acto coercitivo público, en caso de transgresión de las leyes o en el cumplimiento de ellas, según la orden emanada del Poder Jurisdiccional: Artículo 102 A.-La ley organizará el Ministerio Público de la Federación, cuyos funcionarios serán nombrados y removidos por el Ejecutivo, de acuerdo con la ley respectiva. El Ministerio Público de la Federación estará presidido por un Procurador General de la República, designado por el titular del Ejecutivo Federal con ratificación del Senado o, en sus recesos, de la Comisión Permanente.

Artículo 119.-(...) Cada Estado y el Distrito Federal están obligados a entregar sin demora a los indiciados, procesados o sentenciados, así como a practicar 
el aseguramiento y entrega de objetos, instrumentos o productos del delito, atendiendo a la autoridad de cualquier otra entidad federativa que los requiera. Estas diligencias se practicarán, con intervención de las respectivas procuradurías generales de justicia, en los términos de los convenios de colaboración que, al efecto, celebren las entidades federativas.

Artículo 21.-(...) La seguridad pública es una función a cargo de la Federación, el Distrito Federal, los estados y los municipios, en las respectivas competencias que esta Constitución señala. La actuación de las instituciones policiales se regirá por los principios de legalidad, eficiencia, profesionalismo y honradez. La Federación, el Distrito Federal, los estados y los municipios se coordinarán, en los términos que la ley señale, para establecer un sistema nacional de seguridad pública.

Dadas todas las bases metodológicas constitucionales arriba mencionadas, debe ahora presentarse el derecho administrativo de manera coherente, armónica, unitaria, concebido como un todo para administrar, en él y por él, los derechos fundamentales del hombre.

\section{E) Los órganos del modelo operativo en las entidades federativas y municipios}

Bajo el concepto de descentralización política, las 32 entidades federativas (incluyendo al Distrito Federal) y 2435 municipios, mantienen, por disposición del artículo 49 constitucional y de los artículos 115, párrafo primero, 122 párrafo primero, los mismos órganos del modelo operativo o Estado federal, consistiendo éste en dividir su poder en: legislativo, ejecutivo y judicial; el 115 ordena así mismo que tal descentralización política se inicie desde la organización territorial y administrativa del municipio.

La competencia de esos poderes, tal como lo hemos mencionado, se da mediante el criterio residual establecido en el ya mencionado artículo 124 constitucional.

En el criterio residual se excluyen determinadas prohibiciones para las entidades federativas, según se lee en los artículos 117, 118, 120 y 121 y se excluyen también facultades específicas a favor de los municipios.

Las prohibiciones sobresalientes que se dan con el propósito de mantener el principio de unidad del Estado federal, son: Celebrar alianza, tratado o coalición con otro Estado ni con las Potencias extranjeras; acuñar moneda, emitir papel moneda, estampillas, ni papel sellado; gravar el tránsito de personas o cosas que atraviesen su territorio; contraer directa o indirectamente obligaciones o empréstitos con gobiernos de otras naciones, con sociedades o particulares extranjeros, o cuando deban pagarse en moneda extranjera o fuera del territorio nacional; gravar la producción, el acopio o la venta del tabaco en rama, 
en forma distinta o con cuotas mayores de las que el Congreso de la Unión autorice.

Y para mantener la unidad administrativa de todo el orden jurídico, se obliga a las entidades federativas a: artículo 121.-En cada Estado de la Federación se dará entera fe y crédito de los actos públicos, registros y procedimientos judiciales de todos los otros. El Congreso de la Unión, por medio de leyes generales, prescribirá la manera de probar dichos actos, registros y procedimientos, y el efecto de ellos, sujetándose a las bases siguientes:

I. Las leyes de un Estado sólo tendrán efecto en su propio territorio, y, por consiguientes, no podrán ser obligatoria fuera de él;

II. Los bienes muebles e inmuebles se regirán por la ley del lugar de su ubicación;

III. Las sentencias pronunciadas por los tribunales de un Estado sobre derechos reales o bienes inmuebles ubicados en otro Estado, sólo tendrán fuerza ejecutoria en éste, cuando así lo dispongan sus propias leyes.

Las sentencias sobre derechos personales sólo serán ejecutadas en otro Estado, cuando la persona condenada se haya sometido expresamente o por razón de domicilio, a la justicia que las pronunció, y siempre que haya sido citada personalmente para ocurrir al juicio;

IV. Los actos del estado civil ajustados a las leyes de un Estado, tendrán validez en los otros; $y$

V. Los títulos profesionales expedidos por las autoridades de un Estado, con sujeción a sus leyes, serán respetados en los otros.

Hasta aquí las acotaciones, excepciones, obligaciones y límites al criterio residual establecido en la interpretación del artículo 124 constitucional, para dar competencia a las entidades federativas y los municipios.

Bajo el criterio residual que de manera lógica se da en dicho artículo, lo repetimos, a favor de las entidades federativas, existe también otro universo expreso (en el universo del criterio residual) a favor de los municipios.

Ese universo expreso se encuentra especificado en el artículo 115 constitucional, y también de manera metodológica, se dan las bases de la organización administrativa de ese criterio residual.

El poder legislativo de cada entidad está facultado para expedir normas generales sobre el desempeño de ciertas funciones o la prestación de ciertos servicios a cargo de los municipios, en tanto éstos se encuentran facultados para emitir la reglamentación administrativa a tales normas generales.

Leyes generales y reglamentos administrativos tienen determinadas

A \& C R. de Dir. Administrativo \& Constitucional, Belo Horizonte, ano 8, n. 31, p. 96-123, jan./mar. 2008 
bases que respetar para la emisión y reglamentación de las mismas.

Bajo el principio de que: Los municipios estarán investidos de personalidad jurídica y manejarán su patrimonio conforme a la ley.

Los ayuntamientos tendrán facultades para aprobar, de acuerdo con las leyes en materia municipal que deberán expedir las legislaturas de los Estados, los bandos de policía y gobierno, los reglamentos circulares y disposiciones administrativas de observancia general dentro de sus respectivas jurisdicciones, que organicen la administración pública municipal, regulen las materias, procedimientos, funciones y servicios públicos de su competencias y aseguren la participación ciudadano vecinal.

El municipio libre, conforme al artículo 115 constitucional, como base de la descentralización política nacional, tiene competencia constitucional sobre los siguientes aspectos, según se lee en las siguientes fracciones:

I. Están investidos de personalidad jurídica, pueden manejar su patrimonio, dirimen las controversias entre dicha administración y los particulares,

II. Los municipios tendrán a su cargo las funciones y servicios públicos siguientes: a) agua potable, drenaje, alcantarillado, tratamiento y disposición de sus aguas residuales; alumbrado público; limpia, recolección, traslado, tratamiento y disposición final de residuos; mercados y centrales de abasto; panteones; rastro; calles, parques y jardines y su equipamiento; seguridad pública, en los términos del artículo 21 de esta constitución, política preventiva municipal y tránsito; los demás que las legislaturas locales determinen según las condiciones territoriales y socioeconómicas de los municipios, así como su capacidad administrativa y financiera.

III. Los municipios administrarán libremente su hacienda, la cual se formará de los rendimientos de los bienes que les pertenezcan, así como de las contribuciones y otros ingresos que las legislaturas establezcan a su favor, y en todo caso:

a) Percibirán las contribuciones, incluyendo tasas adicionales, que establezcan los Estados sobre la propiedad inmobiliaria, de su fraccionamiento, división, consolidación, traslación y mejora así como las que tengan por base el cambio de valor de los inmuebles. Los municipios podrán celebrar convenios con el Estado para que éste se haga cargo de algunas de las funciones relacionadas con la administración de esas contribuciones; 
b) Las participaciones federales, que serán cubiertas por la Federación a los municipios con arreglo a las bases, montos y plazos que anualmente se determinen por las legislaturas de los Estados; y

c) Los ingresos derivados de la prestación de servicios públicos a su cargo.

IV. Los municipios, en los términos de la leyes federales y estatales relativas, estarán facultados para:

a) Formular, aprobar y administrar la zonificación y planes de desarrollo urbano municipal;

b) Participar en la creación y administración de sus reservas territoriales;

c) Participar en la formación de planes de desarrollo regional, los cuales deberán estar en concordancia con los planes generales de la materia. Cuando la Federación o los Estados elaboren proyectos de desarrollo regional deberán asegurar la participación de los municipios;

d) Autorizar, controlar y vigilar la utilización del suelo en elámbito de su competencia, en sus jurisdicciones territoriales;

e) Intervenir en la regularización de la tenencia de la tierra urbana;

f) Otorgar licencias y permisos para construcciones;

g) Participar en la creación y administración de zonas de reservas ecológicas y la elaboración y aplicación de programas de ordenamiento en esta materia;

h) Intervenir en la formulación y aplicación de programas de transporte público de pasajeros cuando afecten su ámbito territorial; e

i) Celebrar convenios para la administración y custodia en las zonas federales.

Todo lo anterior se da en armonía constitucional y administrativa entre las competencias constitucionales de los órganos del modelo operativo o Estado federal. En este aspecto armónico, sistemático también se encuentra el derecho administrativo municipal, que a su vez puede aplicarse e interpretarse desde la perspectiva de la teoría sistémica del derecho.

\section{F) Teorética administrativa}

Mencionados todos los aspectos de la estructura interna de la teo- 
ría sistémica, tanto sólo nos falta explicar la parte relativa a la teorética administrativa.

Debemos aceptar que ésta se encuentra unida a la teoría del Estado o de la cosa publica, pasando por los principios de la teoría constitucional.

Dentro de la teoría administrativa, conviene, para el mejor desarrollo de nuestro tema, detenernos aunque sea en forma breve no en esclarecer la naturaleza del Estado sino únicamente en los aspectos jurídicos del mismo porque se vinculan directamente con la teoría sistémica del derecho, eliminando al Estado como objeto como simple relación de eventos.

Nuestra teoría se refiere a concebir jurídicamente al Estado como un sujeto de derecho, tal como lo desarrolló, finalmente, Jellinek. ${ }^{8}$

El concepto de sujeto de derecho es un concepto puramente jurídico y no significa cualidad real que de suyo esté ligada a los hombres, sino que, como cualquier concepto jurídico, es por su naturaleza una relación. Que el hombre es un sujeto de derecho, quiere decir que se encuentra con el orden jurídico en una relación que está determinada por normas de igual naturaleza.

Sujeto en sentido jurídico, es por tanto, no una esencia, no una sustancia, sino una capacidad creada mediante la voluntad del orden jurídico.

Capacidad creada mediante la voluntad del orden jurídico, para aplicarse a los hombres que viven en determinado territorio, es ese nuestro concepto de Estado.

La aplicación concreta, funcional, de esa voluntad del orden jurídico se da mediante el derecho administrativo.

El conocimiento jurídico en este caso ha de unirse, más bien, a los resultados del conocimiento del Estado como fenómeno real. Si el Estado es una unidad colectiva, una asociación espiritual de hombres y de fines, y esta unidad no es una ficción, sino una forma necesaria de síntesis de nuestra conciencia que, como todos los hechos de la misma, forma la base de nuestras instituciones, entonces tales unidades colectivas no son menos capaces de adquirir subjetividad jurídica que los individuos humanos.

Mediante la elevación de una unidad colectiva (sujeto de derecho), no creamos una sustancia ficticia que no existiera antes y a la cual se proclama como una esencia a que ha de ir unido el orden jurídico, sino que existen de este modo todas las unidades que el derecho construye como sujetos,

8 Georg Jellinek, Teoría general del Estado, Universidad Iberoamericana, México, 2003, p. 99. 
entre ellos el derecho administrativo.

El Estado desde su aspecto jurídico, según las anteriores observancias críticas, no puede considerarse sino como sujeto de derecho, y en este sentido, está próximo al concepto de la corporación en el que es posible subsumirlo. El sustrato de ésta lo forman hombres que constituyen una unidad de asociación cuya voluntad directora está asegurada por los miembros de la asociación misma.

El concepto de la corporación es un concepto puramente jurídico, al cual, como a todo concepto de derecho, no corresponde nada objetivamente perceptible en el mundo de los hechos; es una forma de síntesis jurídica para expresar las relaciones jurídicas de la unidad de la asociación y su enlace con el orden jurídico. Si se atribuye al Estado como a la corporación jurídica el carácter de personalidad, no se hace uso de una hipóstasis o ficción, pues personalidad no es otra cosa que sujeto de derecho, y significa como hemos dicho, una relación de una individualidad particular o colectiva con el orden jurídico.

Así, desde esta perspectiva debe interpretarse en su totalidad el derecho administrativo, es decir, tomando en cuenta sus bases filosóficas, en particular la filosofía jurídica, sus principios y argumentos lógicos, la metodología de su organización operativa y la teoría que hace la síntesis de cada una de las partes. Tal es en un resumen simplificado la explicación del derecho administrativo mexicano, de acuerdo con sus bases constitucionales.

IV Crítica. Equilibrio y desequilibrio en el modelo operativo mexicano

El poder, como tal, se orienta y desorienta en la consecución de sus fines para los que fue creado. Como fuerza que es, obedece más a las leyes físicas de la acción y de la reacción que a las pautas de su creador. Requiere - de manera permanente - de la brújula interna del derecho, para arribar en el cumplimiento de su cometido, al espíritu y letra del pacto constitucional.

Parodiando al Obispo de Hipona, nos preguntaremos: ¿qué es el poder sin justicia? ¿Qué son los reinos sin justicia? - Se preguntaba y respondía San Agustín —, sino una execrable banda de ladrones.

Pues bien, el poder estatuido en el modelo operativo mexicano mejor dicho - la división tridimensional de ese poder, concebido bajo la teoría del encuentro del equilibrio en competencias y en funciones, según

A \& C R. de Dir. Administrativo \& Constitucional, Belo Horizonte, ano 8, n. 31, p. 96-123, jan./mar. 2008 
la expresión de José Luis Garza Rodríguez, ${ }^{9}$ ha perdido ya los principios teóricos para mantenerse en esa situación. Tales principios, relativos a la competencia y funciones específicas, acotadas, definidas - en mesura con los principios lógicos de identidad y no contradicción — limitadas a: legislar para el legislativo, ejecutar para el ejecutivo y juzgar para el judicial, están a la derivada. Las llaves y candados — pesos y contrapesos — para mantener a cada poder en equilibrio, no son suficientes. La invasión de competencias y funciones ha comenzado.

No es el apocalipsis del orden jurídico mexicano, pero quizá, sólo quizá, estemos escuchando los sonidos de las primeras trompetas.

El orden jurídico tiene aún modos y formas lógicas para corregir antinomias, lagunas e incompatibilidades. Ciertamente, está lejos el apocalipsis. Más bien, estamos — en su primera fase —, ante la presencia de un desequilibrio inicial de los eslabones constitucionales que unen al modelo operativo, en su conjunto, y ante el deslizamiento sin horizontes, de parcelas jurídicas que pueden convertirse en fenómenos oncológicos para el sistema jurídico administrativo.

Dígalo si no, las diversas adiciones y reformas ${ }^{10} \mathrm{a}$ que ha sido sometido el artículo 73 constitucional — (de las facultades del Congreso) en algunos casos para adecuarlo, pero las más para arrebatar funciones a las entidades federativas. Tal es el caso de la fracción XXIX-A, en la parte relativa a las contribuciones especiales en que las entidades y municipios productores de los bienes ahí señalados, ni proponen ni reciben, de manera directa, beneficio fiscal desde su origen. Recordemos que tanto la materia prima como el suelo donde estas se producen, están territorialmente especificadas en un municipio o en una entidad. Igual o parecidos ejemplos se dan en aguas, minería, materia prima en cerveza, arena sílica en cemento, etc. Federación rica, municipios pobres.

Otros casos se dan en algunas instituciones jurídicas, creadas con propósitos doctrinales de mantener el equilibrio del poder, cuando alguno de ellos maneja tal figura de manera inapropiada o con un uso excesivo del beneficio propio. Así, el tiempo en promulgación y publicación de leyes, se manipula, en este caso, por el poder ejecutivo, creando desprestigio

\footnotetext{
9 José Luis Garza Rodríguez, en su tesis doctoral "Los equilibrios del poder", bajo la asesoría de Pedro de Vega García, Universidad Complutense, Madrid, 2006.

10 De acuerdo con Felipe Tena Ramírez, es el artículo constitucional con más adiciones y reformas, desde 1917 hasta 1994, lleva 32 impactos legislativos.
} 
institucional a la otra parte.

Ni que decir del Ministerio Público de la Federación, léase Procurador General de la República, institución creada para dar legalidad, seguridad jurídica, y desde nuestra perspectiva teórica representa la institución metodológica per se para la eficacia del orden jurídico total. La Procuraduría General de la República, las instituciones armadas y de seguridad pública, son, dentro de la teoría sistémica del derecho una etapa metodológica en el aparato estatal, en el estado de derecho. Es la esencia teórica y material del Estado, pues sus actos dan el sello de la justicia. No considerarlo así, el Estado se convertiría en una gavilla de policías, en una banda de ladrones.

Mencionaremos para concluir este trabajo, la proliferación de los organismos autónomos constitucionales, cuya presencia tiende al desequilibrio institucional. Tales entes sustraen espacios que le son propios a otro poder, están fuera de toda rendición de cuentas y pulverizan el significado integral de la judicialización plena — de todo el sistema - , por parte del poder judicial. Anotaremos, sin profundizar en ello, los ejemplos siguientes: Instituto Federal Electoral, Tribunal Electoral, Consejo de la Judicatura Federal, Instituto Federal de Acceso a la Información Pública, Tribunal Fiscal de la Federación, los sujetos de juicio político.

En concordancia con este tema, mencionaré - con respeto y con afecto - el nombre de Julio Rodolfo Comadira: ${ }^{11}$ "juricidad representa la idea de que el accionar de la administración pública procura, necesariamente, el respeto de todo el orden jurídico. La juricidad nuclea, insiste, Comadira, todo el sistema normativo, desde los principios generales del derecho, la Constitución Nacional hasta los simples procedimientos administrativos. Nada ni nadie puede salirse del concepto integral de juricidad".

Informação bibliográfica deste texto, conforme a NBR 6023:2002 da Associação Brasileira de Normas Técnicas (ABNT):

CISNEROS FARÍAS, Germán. Una Interpretación Sistémica del Derecho Administrativo Mexicano, de acuerdo con sus Bases Constitucionales. A\&C Revista de Direito Administrativo e Constitucional, Belo Horizonte, ano 8, n. 31, p. 96-123, jan./mar. 2008.

11 Julio Rodolfo Comadira, Derecho Administrativo. Otros estudios, Abeledo-perrot, Buenos Aires, 2004, p. 279.

A \& C R. de Dir. Administrativo \& Constitucional, Belo Horizonte, ano 8, n. 31, p. 96-123, jan./mar. 2008 
A \& C R. de Dir. Administrativo \& Constitucional, Belo Horizonte, ano 8, n. 31, p. 96-123, jan./mar. 2008 